\title{
PathEx: a novel multi factors based datasets selector web tool
}

\author{
Eric Bareke ${ }^{1 *}$, Michael Pierre ${ }^{1}$, Anthoula Gaigneaux¹, Bertrand De Meulder', Sophie Depiereux', Naji Habra², \\ Eric Depiereux ${ }^{*}$
}

\begin{abstract}
Background: Microarray experiments have become very popular in life science research. However, if such experiments are only considered independently, the possibilities for analysis and interpretation of many life science phenomena are reduced. The accumulation of publicly available data provides biomedical researchers with a valuable opportunity to either discover new phenomena or improve the interpretation and validation of other phenomena that partially understood or well known. This can only be achieved by intelligently exploiting this rich mine of information.

Description: Considering that technologies like microarrays remain prohibitively expensive for researchers with limited means to order their own experimental chips, it would be beneficial to re-use previously published microarray data. For certain researchers interested in finding gene groups (requiring many replicates), there is a great need for tools to help them to select appropriate datasets for analysis. These tools may be effective, if and only if, they are able to re-use previously deposited experiments or to create new experiments not initially envisioned by the depositors. However, the generation of new experiments requires that all published microarray data be completely annotated, which is not currently the case. Thus, we propose the PathEx approach.

Conclusion: This paper presents PathEx, a human-focused web solution built around a two-component system: one database component, enriched with relevant biological information (expression array, omics data, literature) from different sources, and another component comprising sophisticated web interfaces that allow users to perform complex dataset building queries on the contents integrated into the PathEx database.
\end{abstract}

\section{Background}

Although there has been a trend whereby many researchers widely use microarray technologies, less is done computationally to interpret and validate biological hypotheses formulated from inherent investigation results. Continued microarray data deposit and revision of genome annotations are important to supplement previously submitted microarray metadata. While the advent of microarray technologies and an increasing number of analysis methods present an opportunity to better understand life mechanisms, exploitation of microarray data and the choice of analysis methods remain challenges. The idea behind the development of PathEx originates from a benchmarking study we

\footnotetext{
* Correspondence: eric.bareke@fundp.ac.be; eric.depiereux@fundp.ac.be 'Molecular Biology Research Unit (URBM), University of Namur - FUNDP, Namur, Belgium

Full list of author information is available at the end of the article
}

conducted comparing microarray statistical analysis methods [1]. During the study, it was found that some methods focusing on finding gene groups might require many replicates. For a researcher considering conducting a microarray analysis, one consideration should be taken into account: the dataset of interest.

At this level, the challenges include (a) how to effectively and more easily obtain a dataset with the number of replicates necessary for the analysis method chosen and (b) how to select a dataset for a specific purpose (e. g., study of a specific pathology and study of a specific drug response) to increase the statistical power of the analysis method. One way to effectively meet these needs would be to consider re-using previously deposited microarray data from the same or different studies (with different biological hypotheses) without necessarily conducting new experiments.
C Biomed Central

C 2010 Bareke et al; licensee BioMed Central Ltd. This is an Open Access article distributed under the terms of the Creative Commons Attribution License (http://creativecommons.org/licenses/by/2.0), which permits unrestricted use, distribution, and reproduction in any medium, provided the original work is properly cited. 
We propose here a novel web tool that combines information from microarray data, the literature and omics technologies. Its main objective is to allow for instantaneous selection and generation of datasets of interest by drawing relevant samples files from major publicly available microarray repositories and using simple but biologically meaningful keywords to query the underlying database. PathEx provides biologists (with no or limited pre-knowledge of the structure and organization of the microarray data) with an intuitive web interface to generate datasets for validation of existing studies, discovery of new phenomena or complementation of hypotheses regarding phenomena only partially understood.

Many researchers must often manually retrieve or use certain tools available to retrieve microarray data from public repositories. However, such tools are most often limited to pre-knowledge of the structures and formats of the deposited microarray data.

Several tools proposed are mainly either retrieval tools (Microarray Retriever (MaRe) [2]) or full integrated but manufacturer-oriented analysis tools (combining retrieval and analysis tools: EzArray [3] and SiPaGene [4]). However, none have the enhanced ability to allow researchers to automatically select data of interest by focusing on certain biological factors that were not necessarily those provided in the microarray metadata.

Unlike existing tools, the power of PathEx is its fast processing capability made possible through local storage of all of the data (to avoid the sequential downloading policies and bandwidth limitation associated with most microarray repositories). PathEx also remains unique in that it acts as a point of integration of fully re-organized information from public sources. Furthermore, PathEx is not bound to any microarray manufacturer or type. This allows for the datasets selected by PathEx to be analyzed by any platform associated analysis method.

\section{Construction and Content Rationale for PathEx}

As PathEx does not aim to be yet another microarray retrieval tool and the main goal was to develop a novel concept to offer less exploited opportunities for the analysis of deposited microarray data. Deposited microarray data comes with description files (though these files are sometimes incomplete). These metadata files do however contain some key information that can be used to link the microarray data to other biologically related information. We propose here a system that uses this identification metadata to link microarray data to other biological concepts such as Genes, Proteins, Metabolic Pathways and the Literature. By further characterizing previously deposited microarray data; we provide researchers with new opportunities to select interesting datasets by simply using meaningful biological criteria to query the underlying PathEx database.

\section{Implementation of PathEx}

To implement PathEx, we used the popular LAMP bundle, where LAMP stands for Linux operating system http://www.linux.org/; Apache web server http://www. apache.org/, MySQL relational database management system http://www.mysql.com/, PHP http://php.net/ and Perl http://www.perl.org/. A set of new web technologies such as Asynchronous JavaScript And XML (AJAX, http://www.w3schools.com/ajax/default.asp), JavaScript Query (JQuery, http://jquery.com/), MooTools http:// mootools.net/ and JavaScript Object Notation (JSON, http://www.json.org/) was mainly used to increase the system's interactivity, functionality and versatility.

\section{Data Management and Sources for PathEx}

The purpose of PathEx is to allow for custom selection of microarray datasets by completing microarray annotation with biological information from different and heterogeneous sources. While microarray data is automatically drawn from the National Center for Biotechnology Gene Expression Omnibus (NCBI GEO) [5] and European Bioinformatics Institute Array Express (EBI AE) [6-9], the biological information used to further characterize that data is mainly taken from major omics databases/databanks. The idea is to establish a link between microarray metadata and other widely used cross-reference entries, opening up new complex query possibilities. The database component of PathEx currently includes gene information from the NCBI (through Entrez Gene [10] system) and Kyoto Encyclopedia of Gene and Genomes (KEGG) [11-13], ENSEMBL [14-20], H-InvDB [21,22], Vertebrate Genome Annotation (Vega) $[23,24]$, protein information from UniProt/Swiss-Prot [25] and ENSEMBL and metabolic pathway information from KEGG Pathways.

However, one of the challenges we faced when dealing with publicly available biological data was the lack of appropriate tools to organize that data and overcome critical issues such as different file formats, ontologies, structures and accessibilities, lack of information about the contents provided (e.g. KEGG) and incomplete annotation.

Although some sources have opened up their contents to the public by different means such as application programming interfaces (API) and other programmatic tools, the issues mentioned above hamper automated retrieval processes.

To overcome these constraints and provide researchers with an automated criteria-driven dataset selector, we developed a set of complex tools to deal with these 
issues through step-by-step conversion of the contents into open formats and collection of the relevant data to be integrated into the database. The power of these tools relies on how they effectively handle different constraints (e.g. data formats, data structures, accessibility) by independently importing locally and converting all required data to populate the PathEx database.

To ensure the reliability and quality of the data collected, a team of biology experts scrutinized and crosschecked it wherever necessary.

\section{Architecture and Design of PathEx}

The PathEx architecture is divided into three main components (Figure 1): The Processing Logic, The Contents Logic and The Navigator Logic. The Processing Logic has four interdependent utilities (Data Mining Utility, Integration Utility, Query Handler Utility and Updater Utility), The Contents Logic has two storage approaches (Database and Files Repository) and The Navigator Logic has several interfaces (Query Settings, Dataset Builder, Dataset Cart and Global Datasets Manager).

\section{The PathEx Processing Logic}

The PathEx Processing Logic is responsible for:

1. Federation of: a. Basic microarray data (platforms, experiments and samples) and associated sample raw data from GEO Simple Omnibus Format in Text (SOFT, http://www.ncbi.nlm.nih.gov/geo/info/ soft2.html\#SOFTformat) files and AE MicroArray and Gene Expression tab (MAGE-TAB) [26]) files,

b. Additional reviewed microarray metadata, not primarily envisioned by the experiment owners (biological tags: sex, tissue, organ) and

c. Biological information (genes, proteins, metabolic pathways and literature information),

2. Remote change tracking and updating whenever required,

3. PathEx user and query management and

4. PathEx database integration.

As one of the back end components of PathEx, The Data Mining Utility provides a set of algorithms to extract, parse, organize, correlate and convert relevant information: Microarray data (e.g. .CEL files) and metadata, Genes, Proteins, Pathways and Literature information. The Integration Utility manages a relational database (Figure 2) component by loading into and updating it with appropriate structured data. The Query

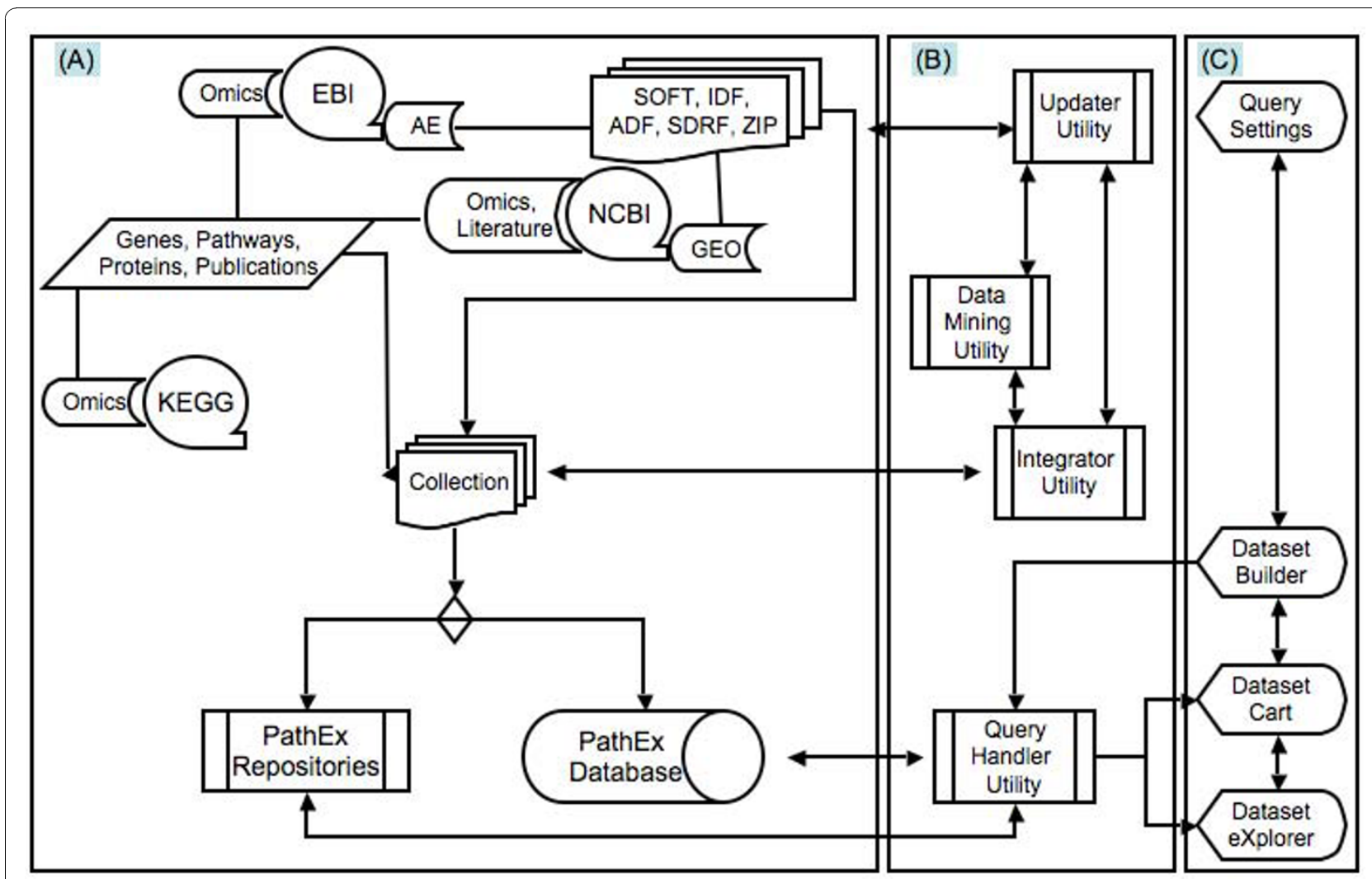

Figure 1 PathEx system architecture (PathEx main process communications) 


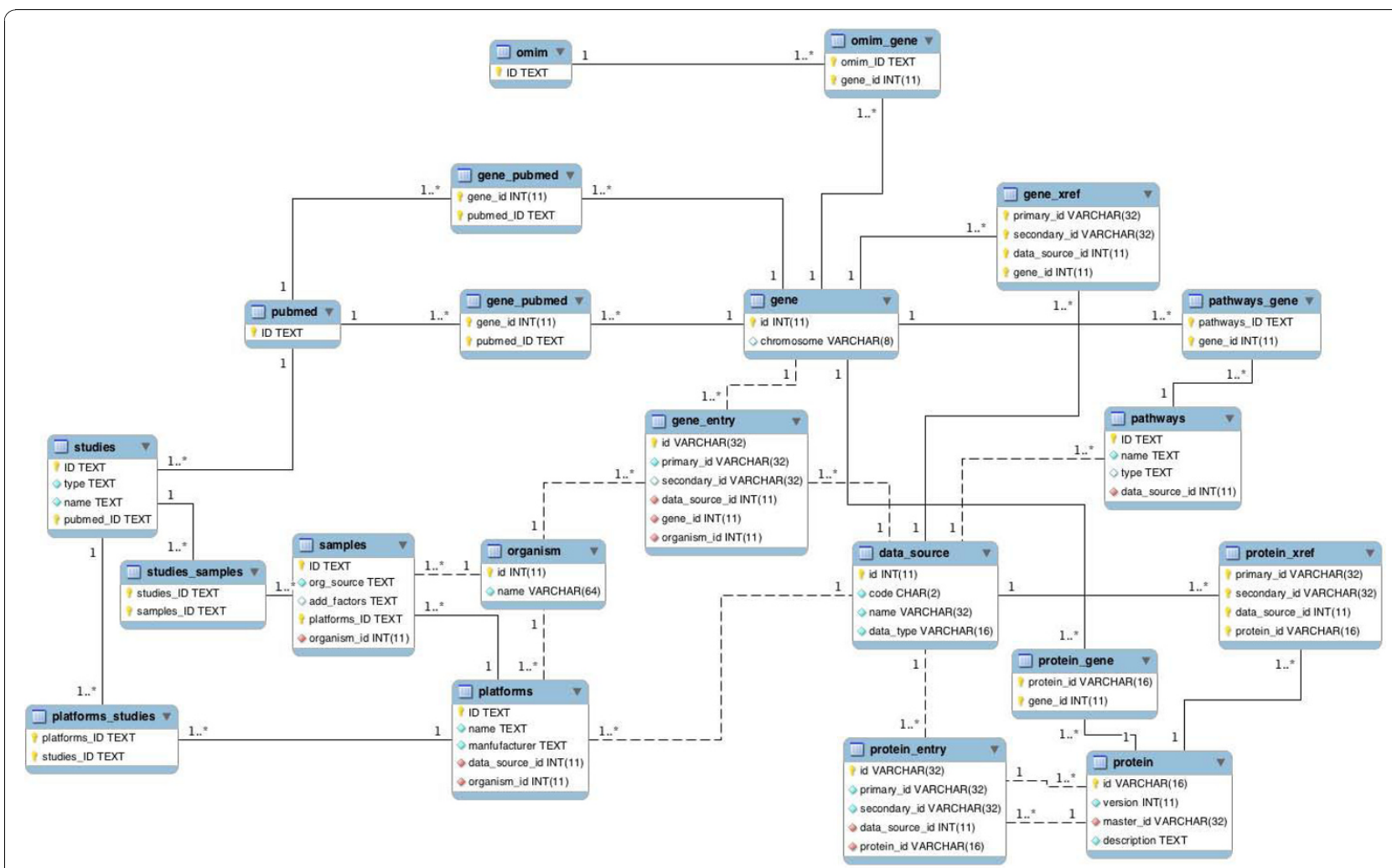

Figure 2 Simplified PathEx Database Enhanced Entity Relationship Data Model (EER DM)

Handler Utility that negotiates the dataset build by checking submitted selection criteria and filters and invoking necessary sample files to build a dataset handles all user queries. PathEx, through the Updater Utility, provides a schema-evolution service that is valuable because the ongoing revision of biological data and the complexity of bioinformatics schemas imply that they are always evolving.

\section{The PathEx Contents Logic}

This component manages the PathEx data storage system: (a) the File Repositories of microarray data files: SOFT files (from GEO), MAGE-TAB files (from AE) and different biological source files used to enrich microarray characterization and (b) the Database containing structured and related microarray metadata and annotational information. GEO SOFT files contain data tables and the accompanying descriptive information for multiple, concatenated Platforms, Samples, and/or Series records.

The integrated AE MAGE-TAB files consist of four different types of files: (a) A "raw" zip archive contains the raw data files, i.e. the files produced by the microarray image analysis software, such as CEL files for Affymetrix GeneChip, (b) The Array Design Format (ADF) tab-delimited file describes the design of an array, (c) The Investigation Description Format (IDF) tab- delimited file contains top-level information about the experiment including the title, description, submitter contact details and protocols and (d) The Sample and Data Relationship Format (SDRF) tab-delimited file containing the relationships between the samples and arrays, as well as sample properties and experimental factors, as provided by the data submitter.

\section{The Navigator Logic}

This component comprises a set of intuitive, interactive and easy-to-use web interfaces. They provide users with features to customize and select a dataset simply by specifying criteria not initially envisioned by those who deposited the expression array data.

\section{Utility and Discussion}

To conduct a routine microarray study analysis, we need (a) a dataset of interest, (b) an appropriate analysis method and (c) a means to evaluate, interpret and validate the results obtained. Currently, benchmarking studies have often emphasized the importance of selection of the analysis methods. This agrees with our recent benchmarking analysis, where we showed that the choice of appropriate analysis methods is crucial for the accuracy of the expected results. Recently, a re-analysis conducted on Golden Spike data by Pearson [27] outlined the characteristics of an ideal dataset: (a) a realistic 
spike-in concentration, (b) a mixture of up- and downregulated genes, (c) unrelated fold change and intensity and (d) a large number of arrays. Based on these criteria, we believe that custom selection of a dataset to analyze is crucial.

As the principal objective of a microarray analysis is to reduce variability, we should consider unexploited ways to do this, particularly in light of the outcome of several studies $[28,29]$ that postulated a complex relationship between variability and expression level. We think that, without minimizing other sources, variability can be reduced by intelligently selecting a focused dataset (e.g. dataset related to a specific pathway, pathology, organ and other factors)

However, as there are no existing tools to automatically select such a dataset, PathEx constitutes an important tool in this context.

With its enriched content and advanced selection features, PathEx provides simple and easy-to-use interfaces (Figure 3) to help users avoid the burden of thinking about complex queries. It combines flexibility, fast processing, accuracy and an easy-to-understand search system using biological tag criteria.

With its multiple level consecutive query interfaces, PathEx maximizes the user searching process and keeps users informed of each query task filter output at each level of dataset selection within an interactive grid. A user is provided with a specific area and interfaces according to settings chosen on the entrance page. PathEx provides three-level selection interfaces, related consecutively on the organizational levels of the microarray data (platforms, studies and samples). Besides a search area, coupled with a set of filters ("equals", "contain", "does not contain" and others) at each level to allow for criteria-driven selection of datasets, there are advanced features to ease selection such as grouping, sorting and multiselecting.

Through the navigational settings, the user specifies the kind of keywords to query PathEx, to allow PathEx to display a customized interface. This approach was chosen to ease dataset selection and present clear interfaces. Many keyword types can be used to query PathEx (e.g. Accessions: gene IDs, gene symbols, protein IDs, OMIM number, and PubMed IDs; Factors: Metabolic pathway names, pathology names, tissues, organ and experiment types).

For each dataset selection request, a user is given a building ticket to trace the job process and download it when finished. The outcome is a compressed file containing all samples files related to the criteria submitted.

There are two ways of retrieving the datasets generated. Any user may retrieve its own datasets through

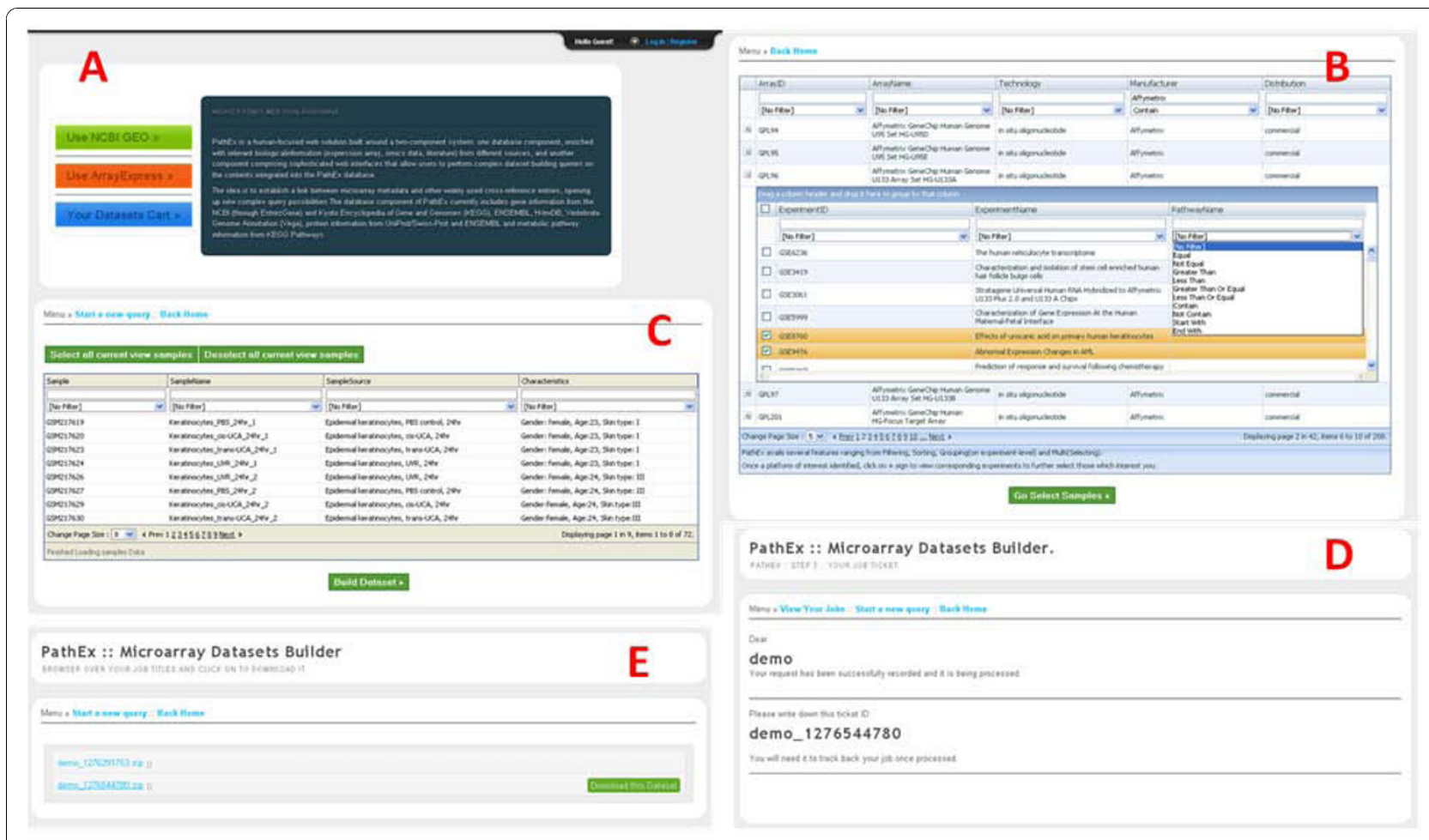

Figure 3 Snapshots of some PathEx navigational interfaces. The above interfaces present: (A) the entrance page after login, (B) the available features such as Multi Selection and Filtering, (C) the dataset build ticketing system and (D) the dataset explorer cart. 
the job cart, as it is name-driven. To evaluate the performance of PathEx, we tested it by selecting a customized dataset related to "lung cancer"from "all" "GEO"experiments of the type "Affymetrix"GeneChip "HG-U133A". By submitting the five highlighted search keys to PathEx and applying appropriate filters, we ended up, in less than 30 seconds, with a dataset of 108 samples.

It is important to note that generated datasets should be analyzed carefully given the known variability due to microarray design and phenotypic differences between studies. However grouping the datasets properly according to some specific characteristics can decrease the variability of a meta-analysis.

\section{Case Study}

In our recently published work[30], we tried to evaluate the effectiveness of PathEx. We used it to try to find genes involved in the metastasis of cancer cells induced by hypoxia. Though many advances have been made in this field, all of the mechanisms involved are still not well understood. It is known that the expression of specific genes is modified in primary tumor cells to detach, migrate and invade surrounding tissues. But the integration of all of the associated data is a problem.

In the first phase of our meta-analysis, we used PathEx to select datasets about metastasis and/or hypoxia. Out of the 24 retrieved datasets, 17 were retained for further analysis (Table 1). As some of the

Table 1 Datasets used in the case study differential analysis.

\begin{tabular}{|c|c|c|c|c|}
\hline $\begin{array}{l}\text { Experiment/Study } \\
\text { Accession numbers }\end{array}$ & Platform & Source & Availability & Experimental conditions \\
\hline E-GEOD-1323 & HG-U133A & $\mathrm{AE}$ & Available & $\begin{array}{l}3 \text { human colorectal cancer derived from a primary tumor VS. } 3 \text { corresponding } \\
\text { lymph node metastases }\end{array}$ \\
\hline E-GEOD-2280 & HG-U133A & $\mathrm{AE}$ & Available & $\begin{array}{l}8 \text { squamous cell carcinoma of the oral cavity VS. } 19 \text { corresponding lymph node } \\
\text { metastases }\end{array}$ \\
\hline \multirow[t]{2}{*}{ E-MEXP-44 } & HG-U95Av2 & $\mathrm{AE}$ & Available & $\begin{array}{l}15 \text { head and neck squamous cell carcinoma VS. } 3 \text { corresponding lymph node } \\
\text { metastases }\end{array}$ \\
\hline & $\begin{array}{c}\text { HG- } \\
\text { UgeneFL }\end{array}$ & & & $\begin{array}{l}12 \text { head and neck squamous cell carcinoma VS. } 11 \text { corresponding lymph node } \\
\text { metastases }\end{array}$ \\
\hline GSE1056 & HG-U95Av2 & GEO & $\begin{array}{c}\text { Not } \\
\text { available }\end{array}$ & $\begin{array}{l}2 \text { human hepatocellular carcinoma under hypoxia for } 2 \text { hours VS. } 2 \text { control } \\
\text { human hepatocellular carcinoma } \\
2 \text { human hepatocellular carcinoma under hypoxia for } 24 \text { hours VS. } 2 \text { control } \\
\text { human hepatocellular carcinoma }\end{array}$ \\
\hline GSE2280 & HG-U133A & GEO & Available & $\begin{array}{l}22 \text { squamous cell carcinoma of the oral cavity VS. } 5 \text { corresponding lymph node } \\
\text { metastases }\end{array}$ \\
\hline GSE2603 & HG-U133A & GEO & Available & 100 primary breast cancer VS. 21 lung metastases \\
\hline GSE3325 & $\begin{array}{c}\text { HG- } \\
\text { U133Plus2.0 }\end{array}$ & GEO & Available & 7 primary prostate cancer VS. 6 metastases \\
\hline GSE4086 & $\begin{array}{c}\text { HG- } \\
\text { U133Plus2.0 }\end{array}$ & GEO & Available & $\begin{array}{l}2 \text { human Burkitt's lymphoma under hypoxia VS. } 2 \text { control human Burkitt's } \\
\text { lymphoma }\end{array}$ \\
\hline GSE468 & HC-G110 & GEO & Available & 13 primary medulloblastomas VS. 10 metastatic medulloblastomas \\
\hline \multirow[t]{2}{*}{ GSE4840 } & HG-U133A & GEO & $\begin{array}{c}\text { Not } \\
\text { available }\end{array}$ & $\begin{array}{l}3 \text { samples from normal melanocyte culture VS. } 12 \text { samples from culture of } \\
\text { cutaneous metastasis of melanoma }\end{array}$ \\
\hline & HG-U133B & & & $\begin{array}{l}3 \text { samples from normal melanocyte culture VS. } 12 \text { samples from culture of } \\
\text { cutaneous metastasis of melanoma }\end{array}$ \\
\hline GSE4843 & $\begin{array}{c}\text { HG- } \\
\text { U133Plus2.0 }\end{array}$ & GEO & $\begin{array}{c}\text { Not } \\
\text { available }\end{array}$ & 45 samples from culture of cutaneous melanoma metastasis \\
\hline GSE6369 & $\begin{array}{c}\text { HG- } \\
\text { U133Plus2.0 }\end{array}$ & GEO & Available & 1 primary prostate carcinoma VS. 1 metastatic prostate carcinoma \\
\hline \multirow[t]{3}{*}{ GSE6919 } & HG-U95Av2 & GEO & Available & 65 primary prostate tumors VS. 25 metastatic prostate tumors \\
\hline & HG-U95B & & & 66 primary prostate tumors VS. 25 metastatic prostate tumors \\
\hline & HG-U95C & & & 65 primary prostate tumors VS. 25 metastatic prostate tumors \\
\hline GSE7929 & HG-U133A & GEO & Available & 11 poorly metastatic melanoma VS. 21 highly metastatic melanoma \\
\hline GSE7930 & HG-U133A & GEO & Available & 3 poorly metastatic prostate tumors VS. 3 highly metastatic prostate tumors \\
\hline GSE7956 & HG-U133A & GEO & Available & 10 poorly metastatic melanoma VS. 29 highly metastatic melanoma \\
\hline GSE8401 & HG-U133A & GEO & Available & 31 primary melanoma VS. 52 melanoma metastasis \\
\hline
\end{tabular}

The above table shows the list of datasets drawn by the PathEx system automatically. 
Table 2 Datasets used in the case study meta-analysis

\begin{tabular}{|c|c|c|c|}
\hline $\begin{array}{l}\text { Meta- } \\
\text { dataset } \\
\text { Name }\end{array}$ & Experimental conditions & $\begin{array}{l}\text { GeneChip } \\
\text { models }\end{array}$ & Datasets \\
\hline $\begin{array}{l}\text { Meta- } \\
\text { dataset } 1\end{array}$ & $\begin{array}{l}\text { Primary tumor, normal tissue, poorly metastatic tissue VS. metastasis, } \\
\text { highly metastatic tissue }\end{array}$ & HG-U133A & $\begin{array}{l}\text { E-GEOD-1323, E-GEOD-2280, GSE2280, GSE2603, } \\
\text { GSE4840 (HG-U133A), GSE7929, GSE7930, } \\
\text { GSE7956, GSE8401 }\end{array}$ \\
\hline $\begin{array}{l}\text { Meta- } \\
\text { dataset } 2\end{array}$ & $\begin{array}{l}\text { Primary tumor, poorly metastatic tissue VS. metastasis, highly metastatic } \\
\text { tissue }\end{array}$ & HG-U133A & $\begin{array}{l}\text { E-GEOD-1323, E-GEOD-2280, GSE2280, GSE2603, } \\
\text { GSE7929, GSE7930, GSE7956, GSE8401 }\end{array}$ \\
\hline $\begin{array}{l}\text { Meta- } \\
\text { dataset } 3\end{array}$ & Primary tumor, normal tissue VS. metastasis & HG-U133A & $\begin{array}{l}\text { E-GEOD-1323, E-GEOD-2280, GSE2280, GSE2603, } \\
\text { GSE4840 (HG-U133A), GSE7929, GSE7956, } \\
\text { GSE8401 }\end{array}$ \\
\hline $\begin{array}{l}\text { Meta- } \\
\text { dataset } 4\end{array}$ & Primary tumor VS. metastasis & HG-U133A & $\begin{array}{l}\text { E-GEOD-1323, E-GEOD-2280, GSE2280, GSE2603, } \\
\text { GSE4840 (HG-U133A), GSE7929, GSE7956, } \\
\text { GSE8401 }\end{array}$ \\
\hline $\begin{array}{l}\text { Meta- } \\
\text { dataset } 5\end{array}$ & Primary tumor VS. metastasis & HG-U133A & $\begin{array}{l}\text { E-GEOD-1323, E-GEOD-2280, GSE2280, GSE2603, } \\
\text { GSE7929, GSE7956, GSE8401 }\end{array}$ \\
\hline $\begin{array}{l}\text { Meta- } \\
\text { dataset } 6\end{array}$ & $\begin{array}{l}\text { Squamous cell carcinoma of the oral cavity VS. corresponding lymph } \\
\text { node metastases }\end{array}$ & HG-U133A & E-GEOD-2280, GSE2280 \\
\hline $\begin{array}{l}\text { Meta- } \\
\text { dataset } 7\end{array}$ & $\begin{array}{l}\text { Normal melanocyte culture, poorly metastatic melanoma, primary } \\
\text { melanoma VS. culture of cutaneous metastasis of melanoma, highly } \\
\text { metastatic melanoma, melanoma metastasis }\end{array}$ & HG-U133A & $\begin{array}{l}\text { GSE4840 (HG-U133A), GSE7929, GSE7956, } \\
\text { GSE8401 }\end{array}$ \\
\hline $\begin{array}{l}\text { Meta- } \\
\text { dataset } 8\end{array}$ & $\begin{array}{l}\text { Poorly metastatic melanoma, primary melanoma VS. culture of } \\
\text { cutaneous metastasis of melanoma, highly metastatic melanoma, } \\
\text { melanoma metastasis }\end{array}$ & HG-U133A & $\begin{array}{l}\text { GSE4840 (HG-U133A), GSE7929, GSE7956, } \\
\text { GSE8401 }\end{array}$ \\
\hline $\begin{array}{l}\text { Meta- } \\
\text { dataset } 9\end{array}$ & $\begin{array}{l}\text { Poorly metastatic melanoma, primary melanoma VS. highly metastatic } \\
\text { melanoma, melanoma metastasis }\end{array}$ & HG-U133A & GSE7929, GSE7956, GSE8401 \\
\hline $\begin{array}{l}\text { Meta- } \\
\text { dataset } 10\end{array}$ & Primary tumor VS. metastasis & HG-U95Av2 & E-MEXP-44 (HG-U95Av2), GSE6919 (HG-U95Av2) \\
\hline $\begin{array}{l}\text { Meta- } \\
\text { dataset } 11\end{array}$ & Hypoxia VS. normoxia & HG-U95Av2 & GSE1056 \\
\hline $\begin{array}{l}\text { Meta- } \\
\text { dataset } 12\end{array}$ & Primary tumor, normoxia VS. metastasis, hypoxia & $\begin{array}{l}\text { HG- } \\
\text { U133Plus2.0 }\end{array}$ & GSE3325, GSE4086, GSE4843, GSE6369 \\
\hline $\begin{array}{l}\text { Meta- } \\
\text { dataset } 13\end{array}$ & Primary tumor VS. metastasis & $\begin{array}{l}\text { HG- } \\
\text { U133Plus } 2.0\end{array}$ & GSE3325, GSE4843, GSE6369 \\
\hline $\begin{array}{l}\text { Meta- } \\
\text { dataset } 14\end{array}$ & Primary prostate cancer VS. metastases & $\begin{array}{l}\text { HG- } \\
\text { U133Plus2.0 }\end{array}$ & GSE3325, GSE6369 \\
\hline
\end{tabular}

Using PathEx features, which allowed combination of samples from different experiment, we automatically created the above datasets.

selected datasets were not available in GEO or AE, we contacted the original authors to obtain them.

In the second phase, we again used PathEx to generate 14 customized meta-datasets from the 17 original datasets (Table 2).

After analysis, our study results were combined, highlighting 183 genes of interest (Figure 4). Out of these genes, 99 are already known in the literature to be involved in cancer, among which 39 in metastasis, while 21 are related to the response to hypoxia. The other genes of interest found by our methodology are now under investigation to determine their role in hypoxiainduced metastasis.

\section{Perspectives for PathEx}

PathEx is currently a human-oriented web tool. It is likely to be extended to other species in the future. Currently indexed biological information such as pathways are limited to one source (KEGG), we are considering integrating other sources such as Wiki Pathways [31] for pathway information, expanding the query options given to users in the event of selective sources due to licensing issues linked to the information owners.

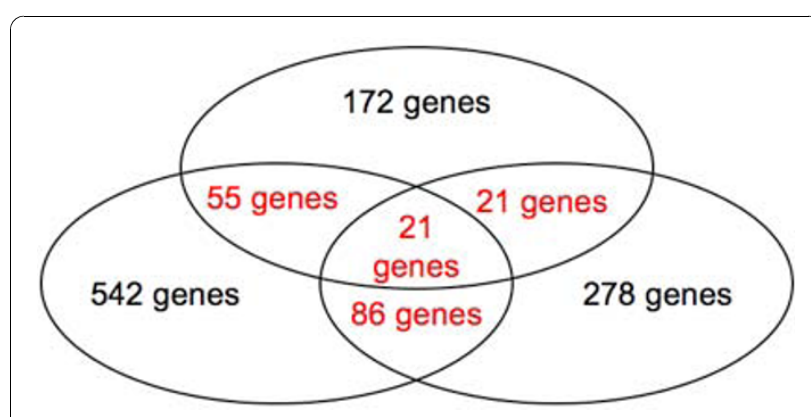

Figure 4 Venn's diagram of interesting differentially expressed genes as revealed by the case study. 
As PathEx is not bound to any analysis method, we are currently developing a fully-automated and integrated Affymetrix web analysis tool to combine PathEx with analysis methods developed by us and proven to be efficient: the Window t-test and PHOENIX [32], interesting tools such as DAVID [33] and tools developed inhouse (GViz and Namek). Besides the reasons stated above, additional factors such as recent redefinition approaches of Affymetrix Chip Definition Files (CDF) [34-36] and a large number of powerful analysis methods published enforce the utility of PathEx. We strongly believe that it will help researchers to automate their dataset selection. The choice will be up to them whether to do a single gene/gene group differential or co-expression analysis or a meta-analysis (Figure 5).

\section{Conclusions}

Publicly available microarray data are rich mines of information. Fully exploiting them may help to understand life mechanisms. However, effective exploitation of this information requires us to further characterize them by crossing their metadata with other biological information.

We present here a database coupled with a web interface that, by intelligently organizing information from different biological sources, will allow researchers to select relevant datasets (mandatory initial step of any routine microarray analysis). We believe this will help to discover, interpret, validate and further develop biological hypotheses without the need to conduct new experiments.

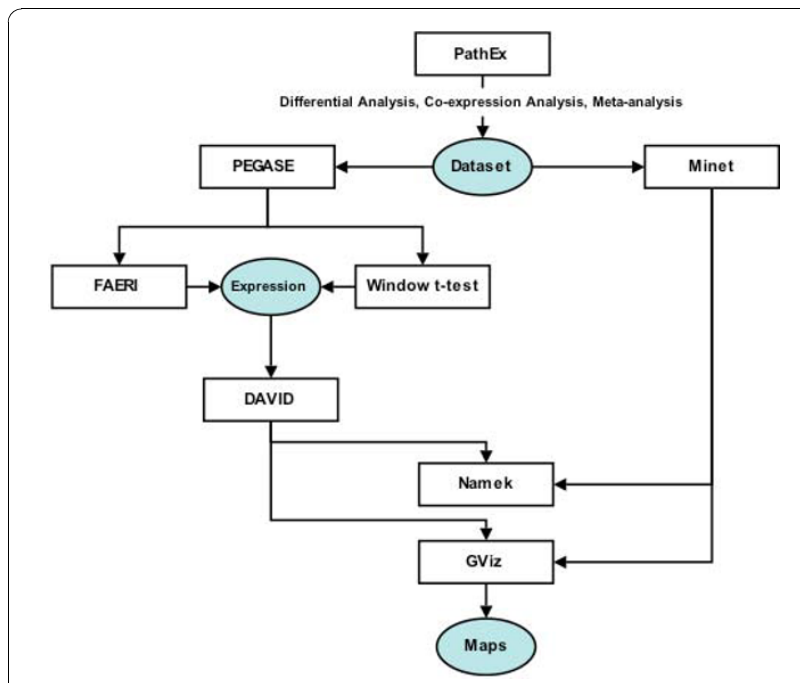

Figure 5 Future planned PathEx development components. The new integrated analysis tool will combine PathEx, proven analysis tools such Minet and DAVID and locally developed tools (PEGASE, FAERI, Window t-test, Namek and GViz).

\section{Availability and Requirements}

PathEx is freely accessible for non-commercial users from http://urbm-cluster.urbm.fundp.ac.be/webapps/ pathex/

Login parameters for testing:

\section{Username: demo \\ Password: $\mathbf{1 3 8 . 4 8}$}

\section{Acknowledgements}

Two grants, one from the University of Namur (FUNDP, Facultés Universitaires Notre Dame de la Paix) and another from the Belgian Government through Belgian Technical Cooperation (BTC), supported this work. Our sincere gratitude goes to Dr. Desire Ndushabandi, the Rector of Kigali Health Institute Rector, for his wise and valuable support and Raphaël Haelars for his technical support.

\section{Author details}

'Molecular Biology Research Unit (URBM), University of Namur - FUNDP, Namur, Belgium. ${ }^{2}$ Research Center in Information Systems Engineering (PReCISE), University of Namur - FUNDP, Namur, Belgium.

\section{Authors' contributions}

EB designed and coded the major part of PathEx, drafted the manuscript and wrote the final version of the manuscript. ED, as the principal project initiator, supervised the project development at all levels, reviewed and approved the last version of the manuscript. $\mathrm{NH}$, as co-director of the project, intervened during technical specification, provided advice on technical choices made, reviewed and approved the last version of the project. AG, BdM, and SD verified the database content quality, tested it and gave comments on the manuscript. MP tested the PathEx database and used it to generate the data used in the article published in BMC Cancer. All authors read and approved the final manuscript.

Received: 14 June 2010 Accepted: 22 October 2010

Published: 22 October 2010

\section{References}

1. De Hertogh B, De Meulder B, Berger F, Pierre M, Bareke E, Gaigneaux A, Depiereux E: A benchmark for statistical microarray data analysis that preserves actual biological and technical variance. BMC Bioinformatics 2010, 11:17.

2. Ivliev AE, t Hoen PA, Villerius MP, den Dunnen JT, Brandt BW: Microarray retriever: a web-based tool for searching and large scale retrieval of public microarray data. Nucleic Acids Res 2008, 36 Web Server:W327-331.

3. Zhu Y, Xu W: EzArray: a web-based highly automated Affymetrix expression array data management and analysis system. BMC Bioinformatics 2008, 9:46.

4. Menssen A, Edinger G, Grun JR, Haase U, Baumgrass R, Grutzkau A, Radbruch A, Burmester GR, Haupl T: SiPaGene: A new repository for instant online retrieval, sharing and meta-analyses of GeneChip expression data. BMC Genomics 2009, 10:98.

5. Barrett T, Edgar R: Gene expression omnibus: microarray data storage, submission, retrieval, and analysis. Methods Enzymol 2006, 411:352-369.

6. Parkinson H, Kapushesky M, Shojatalab M, Abeygunawardena N, Coulson R, Farne A, Holloway E, Kolesnykov N, Lilja P, Lukk M, et al: ArrayExpress-a public database of microarray experiments and gene expression profiles. Nucleic Acids Res 2007, 35 Database:D747-750.

7. Brazma A, Parkinson H, Sarkans U, Shojatalab M, Vilo J, Abeygunawardena N, Holloway E, Kapushesky M, Kemmeren P, Lara GG et al: ArrayExpress-a public repository for microarray gene expression data at the EBI. Nucleic Acids Res 2003, 31(1):68-71.

8. Parkinson H, Sarkans U, Shojatalab M, Abeygunawardena N, Contrino S, Coulson R, Farne A, Lara GG, Holloway E, Kapushesky M, et al: ArrayExpress-a public repository for microarray gene expression data at the EBI. Nucleic Acids Res 2005, 33 Database:D553-555. 
9. Rocca-Serra P, Brazma A, Parkinson H, Sarkans U, Shojatalab M, Contrino S, Vilo J, Abeygunawardena N, Mukherjee G, Holloway E, et al: ArrayExpress: a public database of gene expression data at EBI. C R Biol 2003, 326(1011):1075-1078

10. Maglott D, Ostell J, Pruitt KD, Tatusova T: Entrez Gene: gene-centered information at NCBI. Nucleic Acids Res 2005, 33 Database:D54-58.

11. Kanehisa M, Goto S: KEGG: kyoto encyclopedia of genes and genomes. Nucleic Acids Res 2000, 28(1):27-30.

12. Ogata H, Goto S, Sato K, Fujibuchi W, Bono H, Kanehisa M: KEGG: Kyoto Encyclopedia of Genes and Genomes. Nucleic Acids Res 1999, 27(1):29-34

13. Wixon J, Kell D: The Kyoto encyclopedia of genes and genomes-KEGG. Yeast 2000, 17(1):48-55.

14. Birney E, Andrews D, Bevan P, Caccamo M, Cameron G, Chen Y, Clarke L, Coates G, Cox T, Cuff J, et al: Ensembl 2004. Nucleic Acids Res 2004, 32 Database:D468-470.

15. Hubbard T, Andrews D, Caccamo M, Cameron G, Chen Y, Clamp M Clarke L, Coates G, Cox T, Cunningham F, et al: Ensembl 2005. Nucleic Acids Res 2005, 33 Database:D447-453.

16. Birney E, Andrews D, Caccamo M, Chen Y, Clarke L, Coates G, Cox T, Cunningham F, Curwen V, Cutts T, et al: Ensembl 2006. Nucleic Acids Res 2006, 34 Database:D556-561

17. Hubbard TJ, Aken BL, Beal K, Ballester B, Caccamo M, Chen Y, Clarke L, Coates G, Cunningham F, Cutts T, et al: Ensembl 2007. Nucleic Acids Res 2007, 35 Database:D610-617.

18. Flicek P, Aken BL, Beal K, Ballester B, Caccamo M, Chen Y, Clarke L, Coates G, Cunningham F, Cutts T, et al: Ensembl 2008. Nucleic Acids Res 2008, 36 Database:D707-714.

19. Hubbard TJ, Aken BL, Ayling S, Ballester B, Beal K, Bragin E, Brent S, Chen Y, Clapham P, Clarke L, et al: Ensembl 2009. Nucleic Acids Res 2009, 37 Database:D690-697.

20. Hubbard T, Barker D, Birney E, Cameron G, Chen Y, Clark L, Cox T, Cuff J, Curwen V, Down T, et al: The Ensembl genome database project. Nucleic Acids Res 2002, 30(1):38-41.

21. Yamasaki C, Murakami K, Takeda J, Sato Y, Noda A, Sakate R, Habara T, Nakaoka H, Todokoro F, Matsuya A, et al: H-InvDB in 2009: extended database and data mining resources for human genes and transcripts. Nucleic Acids Res 2009, 38 Database:D626-632.

22. Yamasaki C, Murakami K, Fujii Y, Sato Y, Harada E, Takeda J, Taniya T, Sakate R, Kikugawa S, Shimada M, et al: The H-Invitational Database $(H$ InvDB), a comprehensive annotation resource for human genes and transcripts. Nucleic Acids Res 2008, 36 Database:D793-799.

23. Ashurst JL, Chen CK, Gilbert JG, Jekosch K, Keenan S, Meidl P, Searle SM, Stalker J, Storey R, Trevanion S, et al: The Vertebrate Genome Annotation (Vega) database. Nucleic Acids Res 2005, 33 Database:D459-465.

24. Wilming LG, Gilbert JG, Howe K, Trevanion S, Hubbard T, Harrow JL: The vertebrate genome annotation (Vega) database. Nucleic Acids Res 2008, 36 Database:D753-760.

25. Boeckmann B, Bairoch A, Apweiler R, Blatter MC, Estreicher A, Gasteiger E, Martin MJ, Michoud K, O'Donovan C, Phan I, et al: The SWISS-PROT protein knowledgebase and its supplement TrEMBL in 2003. Nucleic Acids Res 2003, 31(1):365-370.

26. Rayner TF, Rocca-Serra P, Spellman PT, Causton HC, Farne A, Holloway E, Irizarry RA, Liu J, Maier DS, Miller M, et al: A simple spreadsheet-based, MIAME-supportive format for microarray data: MAGE-TAB. BMC Bioinformatics 2006, 7:489.

27. Pearson RD: A comprehensive re-analysis of the Golden Spike data: towards a benchmark for differential expression methods. BMC Bioinformatics 2008, 9:164.

28. Baldi P, Long AD: A Bayesian framework for the analysis of microarray expression data: regularized $\mathrm{t}$-test and statistical inferences of gene changes. Bioinformatics 2001, 17(6):509-519.

29. Berger F, De Hertogh B, Pierre M, Gaigneaux A, Depiereux E: The "Window t test": a simple and powerful approach to detect differentially expressed genes in microarray datasets. Central European Journal of Biology 2008, 3(3):327-344.

30. Pierre M, DeHertogh B, Gaigneaux A, DeMeulder B, Berger F, Bareke E, Michiels C, Depiereux E: Meta-analysis of archived DNA microarrays identifies genes regulated by hypoxia and involved in a metastatic phenotype in cancer cells. BMC Cancer 10:176.

31. Pico AR, Kelder T, van lersel MP, Hanspers K, Conklin BR, Evelo C: WikiPathways: pathway editing for the people. PLoS Biol 2008, 6(7):e184
32. Fabrice Berger BDH, Pierre Michaël, Bareke Eric, Gaigneaux Anthoula, Eric Depiereux: PHOENIX, a web interface for (re)analysis of microarray data. Central European Journal of Biology 2009, 4(4):15.

33. Dennis G Jr, Sherman BT, Hosack DA, Yang J, Gao W, Lane HC, Lempicki RA DAVID: Database for Annotation, Visualization, and Integrated Discovery. Genome Biol 2003, 4(5):P3.

34. Liu H, Zeeberg BR, Qu G, Koru AG, Ferrucci A, Kahn A, Ryan MC, Nuhanovic A, Munson PJ, Reinhold WC, et al: AffyProbeMiner: a web resource for computing or retrieving accurately redefined Affymetrix probe sets. Bioinformatics 2007, 23(18):2385-2390.

35. Gautier L, Moller M, Friis-Hansen L, Knudsen S: Alternative mapping of probes to genes for Affymetrix chips. BMC Bioinformatics 2004, 5:111.

36. Dai M, Wang P, Boyd AD, Kostov G, Athey B, Jones EG, Bunney WE, Myers RM, Speed TP, Akil H, et al: Evolving gene/transcript definitions significantly alter the interpretation of GeneChip data. Nucleic Acids Res 2005, 33(20):e175.

doi:10.1186/1471-2105-11-528

Cite this article as: Bareke et al:: PathEx: a novel multi factors based datasets selector web tool. BMC Bioinformatics 2010 11:528.

\section{Submit your next manuscript to BioMed Central and take full advantage of:}

- Convenient online submission

- Thorough peer review

- No space constraints or color figure charges

- Immediate publication on acceptance

- Inclusion in PubMed, CAS, Scopus and Google Scholar

- Research which is freely available for redistribution 